\title{
Assessment of Lumbar Lordosis and Lumbar Core Strength in Information Technology Professionals
}

\author{
Roma Satish Mehta ${ }^{1}$, Sanket Nagrale ${ }^{1}$, Rachana Dabadghav ${ }^{1}$, \\ Savita Rairikar ${ }^{2}$, Ashok Shayam ${ }^{3}$, Parag Sancheti ${ }^{4}$ \\ ${ }^{1}$ Physiotherapy Department, Sancheti College of Physiotherapy, Pune, India \\ ${ }^{2}$ Sancheti College of Physiotherapy, Pune, India \\ ${ }^{3}$ Orthopaedic Department, Sancheti Institute of Orthopedics and Rehabilitation, Pune, India \\ ${ }^{4}$ Sancheti Institute of Orthopedics and Rehabilitation, Pune, India
}

\begin{abstract}
Study Design: Observational study.
Purpose: To correlate lumbar lordosis and lumbar core strength in information technology (IT) professionals.

Overview of Literature: IT professionals have to work for long hours in a sitting position, which can affect lumbar lordosis and lumbar core strength.

Methods: Flexicurve was used to assess the lumbar lordosis, and pressure biofeedback was used to assess the lumbar core strength in the IT professionals. All subjects, both male and female, with and without complaint of low back pain and working for two or more years were included, and subjects with a history of spinal surgery or spinal deformity were excluded from the study. Analysis was done using Pearson's correlation.

Results: For the IT workers, no correlation was seen between lumbar lordosis and lumbar core strength $(r=-0.04)$; however, a weak negative correlation was seen in IT people who complained of pain $(r=-0.12)$, while there was no correlation of lumbar lordosis and lumbar core in IT people who had no complains of pain $(r=0.007)$.

Conclusions: The study shows that there is no correlation of lumbar lordosis and lumbar core strength in IT professionals, but a weak negative correlation was seen in IT people who complained of pain.
\end{abstract}

Keywords: Information technology professionals; Lumbar lordosis; Lumbar core strength; Flexicurve

\section{Introduction}

Back pain is one of the great human afflictions [1]. The lumbar spine supports the upper body and transmits the weight of the upper body to the pelvis and lower limbs. The normal resting position of the lumbar spine is midway between flexion and extension. Lumbar spine is primarily responsible for posture and stability providing the strength needed for stability especially utilized in static and dynamic postures [1]. Core stability relates to the body region bounded by the abdominal wall, the pelvis, the lower back, and the diaphragm, and its ability to stabilize the body during movement. The main muscles involved include the transverses abdominis, the internal

Received Sep 3, 2015; Revised Dec 28, 2015; Accepted Jan 8, 2016

Corresponding author: Sanket Nagrale

Sancheti Institute College of Physiotherapy, Thube Park, Shivajinagar, Pune 411005, India

Tel: +91-20-2553-9393, Fax: +91-20-2553-9494, E-mail: nagralesanket@gmail.com 
and external oblique, the quadratus lumborum, and the diaphragm. For a human, the diaphragm is the main muscle for breathing as breathing provides an important contribution to core stability for movement and lifting. It is the action of these muscles contracting together upon the incompressible contents of the abdominal cavity (i.e., the internal organs or viscera) that provides support to the spine and pelvis during movement. Typically, the core is associated with the abdominal muscles groups and stability is associated with isometric or static strength [2]. Information technology (IT) professionals perform most of their work on computers, with laptops or desktops, which requires long hours of sitting. Long hours of sitting require more of an increase in muscle activity than standing [3]. Sitting forces the pelvis into more of a posterior pelvic tilt and causes a reduction in the lumbar curve in comparison with standing [3]. Studies have indicated a role for mechanical loads on the etiology of low back pain. Fixed postures and seating postures are also one of the risk factors causing low back pain in sedentary occupations [4]. The objective of this study was to assess lumbar lordosis and lumbar core strength in the IT population and correlate them, and also correlate lumbar lordosis and lumbar core strength in the population who complains of pain and those that do not complain of pain.

\section{Materials and Methods}

Study clearance was obtained from the institutional ethical committee. An observational study was done on IT professionals with 200 IT professionals from different IT companies, out of whom 120 were males and 80 were females with an age range of 23-45 years (range, 31.84 \pm 6.96 years). The participants were provided a questionnaire, and in addition, were assessed for lumbar lordosis and lumbar core strength in a physical exam. All IT people working for more than 2 years, both males and females from the symptomatic and asymptomatic population, were included while the population with any past spine surgeries or spinal deformities were excluded. The purpose and procedure and a written consent was taken. Each participant was made to fill the questionnaire.

\section{Assessing lumbar lordosis}

The subject was in the relaxed standing position. First the bony landmarks were marked as C7, T12, L1, S1, and S2 by the therapist. A Quilters Flexicurve of $60 \mathrm{~cm}$ was used (graduated in $\mathrm{cm}$ and $\mathrm{mm}$ ) and is an instrument used in the assessment of lumbar spine. The Flexicurve was placed carefully on the dorsal aspect of the spine. Readings were plotted on a plain sheet of paper and, the calculation was performed for the lordosis index (lumbar width/lumbar length $\times 100)[5]$.

\section{Assessing lumbar core strength}

The patient was in the prone position. The stabilizer pressure biofeedback (Chattanooga Stabilizer Pressure Biofeedback, CH 153PA 01, Chattanooga/DJO Global Inc., Guildford Surrey, UK) was placed under the abdomen (centered the navel), and the stabilizer was inflated to 70 $\mathrm{mm}$ Hg. The patient performed drawing in maneuver. A decrease in $6-10 \mathrm{~mm} \mathrm{Hg}$ during the drawing in maneuver (without substitution) indicated proper activation of the deep abdominal muscles. It was checked to see if the patient could maintain the pressure drop for up to $10 \mathrm{sec}-$ onds [6].

\section{Results}

In our study we found the degree of lumbar lordosis in female was (13.45 \pm 4.95$)$ and males (13.24 \pm 5.59$)$ and it showed no significant difference between the genders. In our study we also found that the degree of lumbar lordosis had a significant difference between people who had pain $(12.45 \pm 4.06)$ and people who did not have pain $(14.19 \pm 6.24)$. Our study found that there was no significant difference in core strength of males $(63.51 \pm 2.60)$ and females $(63.4 \pm 2.59)$, and that there was no significant difference in core strength of subjects who complained of pain (63.41 \pm 2.44$)$ and those who had no complaints of pain (63.47 \pm 2.74$)$. In our study we found that there was no correlation between lumbar lordosis and core strength $(r=-0.04)$ in IT professionals (Fig. 1).

Out of 71 people who complained of low back pain, for $63 \%$ back pain was aggravated from continuous sitting while for the remaining $37 \%$, back pain was not aggravated due to continuous sitting. The people who complained of pain showed a weak negative correlation $(r=-0.12)$ (Fig. 2 ) with lumbar lordosis with increase in pain as the core strength is reduced, as compared to people who had no complaints of pain, and had no correlation of lumbar lordosis and lumbar core strength ( $r=0.007)$ (Fig. 3 ). 


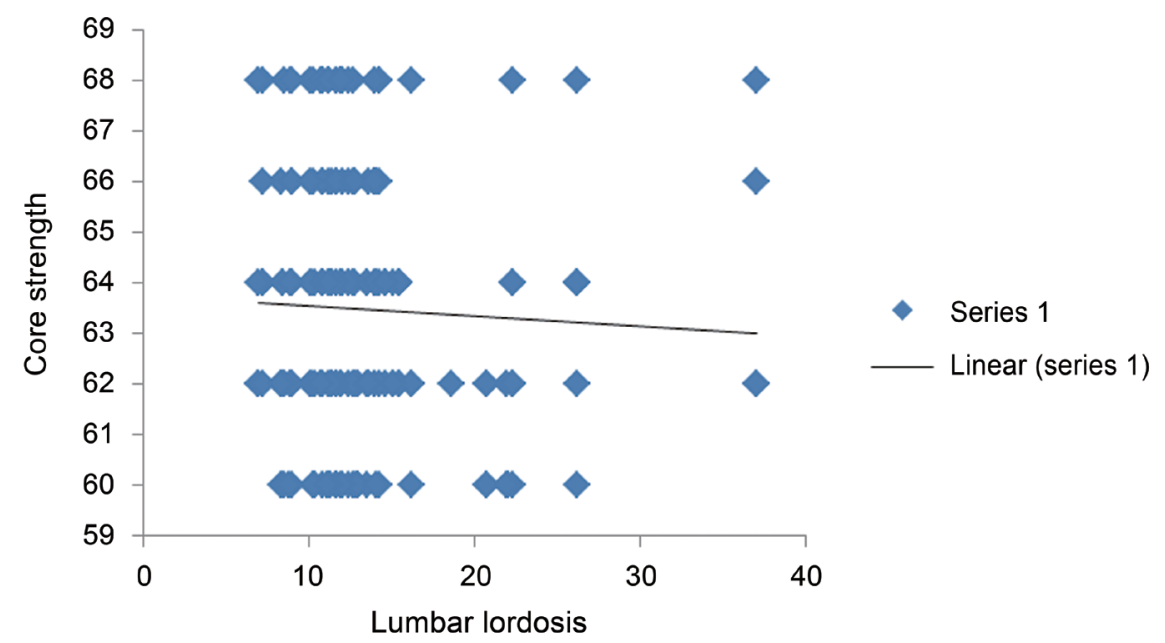

Fig. 1. The study shows that there is no correlation between lumbar lordosis and core strength $(r=-0.04)$ for the overall information technology population.

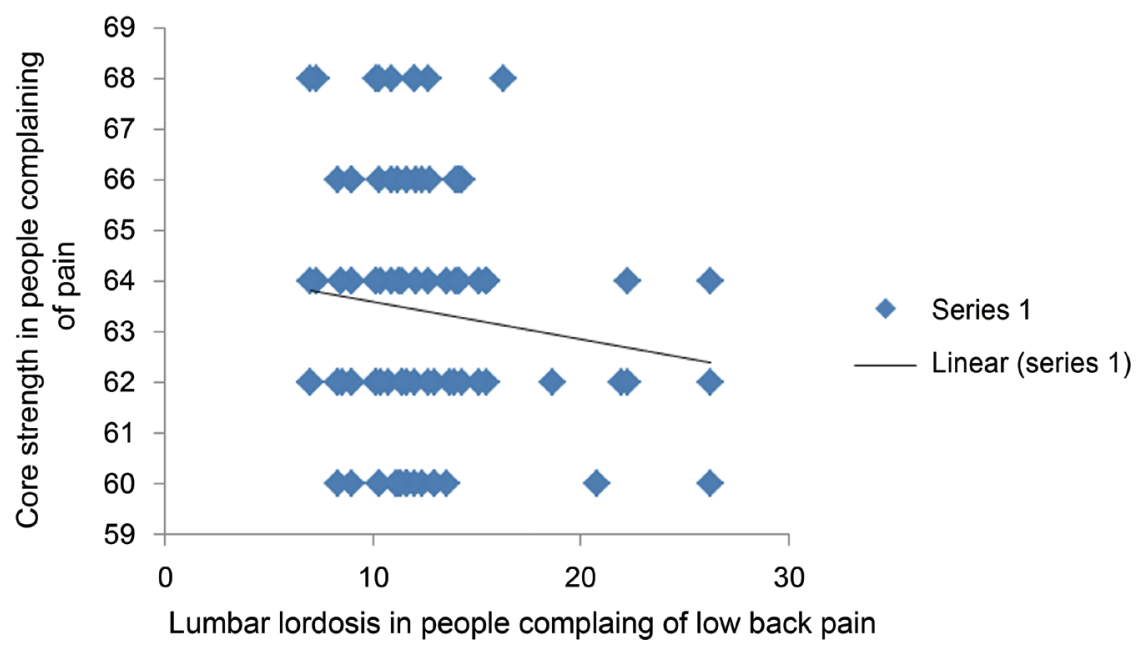

Fig. 2. The correlation graph indicates a weak negative correlation between lumbar lordosis and core strength for people complaining of low back pain $(r=-0.12)$.

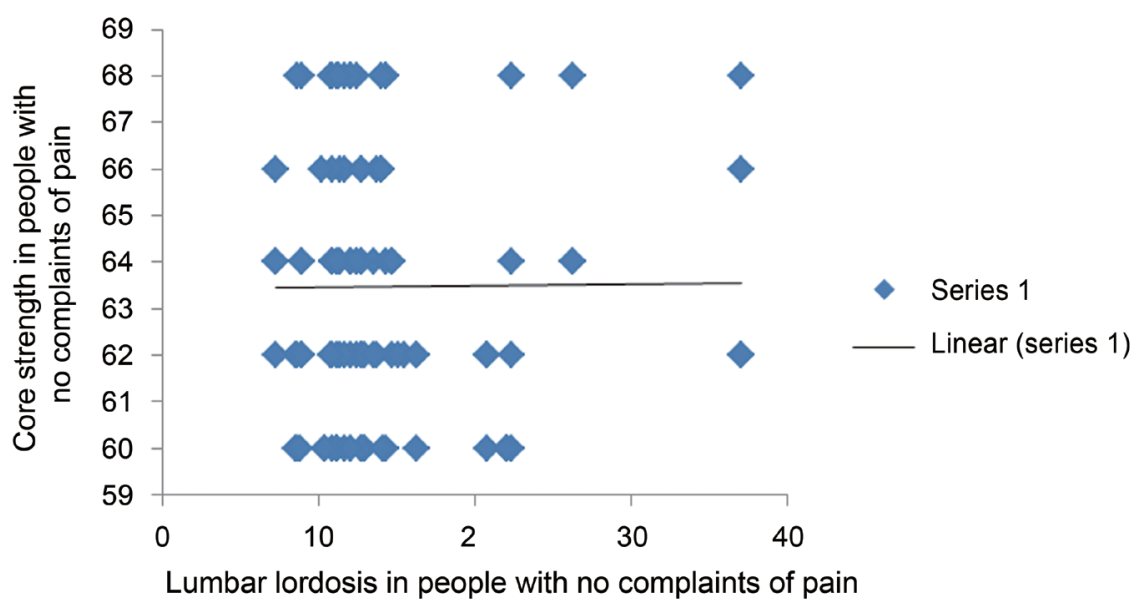

Fig. 3. The correlation graph indicates no correlation ( $r=0.007)$ between lumbar lordosis and lumbar core strength in information technology people who have no complaints of low back pain. 


\section{Discussion}

In our study the degree of lumbar lordosis in the female subjects was (13.45 \pm 4.95$)$ and in males was found to be (13.24 \pm 5.59$)$, and thus there was no significant difference in the degree of lordosis in males versus females. In another study in 2011, which examined healthy subjects, the degree of lumbar lordosis in females was reported to be 12 degrees more than males [7], which is not in agreement with our results.

In our study the degree of lumbar lordosis had a significant difference between people who had pain (12.45 \pm 4.06$)$ and people who did not have pain $(14.19 \pm 6.24)$. In the previous studies, the degree of lumbar lordosis was not different between normal subjects and patients with low back pain in the survey done by Nourbakhsh et al. [8].

In our study of IT population, we had overall values for lumbar lordosis of 13.29 \pm 5.33 . Studies by Youdas et al. [9] and Nourbakhsh et al. [8], using flexible curve method, reported the range of $37 \pm 11$ and $37 \pm 13$ degrees for lumbar lordosis, respectively, for the non-IT, general population. This is suggestive that because of long sitting hours the pelvis is tilted posteriorly, which in turn reduces the lordosis

In terms of number of hours worked per day, for the general population, $73 \%$ works for 7-9 hours, followed by $19 \%$ of population working for more than 10 hours, $6 \%$ of population working for 5-6 hours, and followed by $2 \%$ of population working for 3-4 hours. Hence the study shows that there are higher percentages of population who have 7-9 hours of working a day. For the IT population, working for similar number of hours as the general population, $37 \%$ has continuous sitting for $2-4$ hours, followed by $35 \%$ of people continuously sitting for $5-7$ hours, $22 \%$ for $8-10$ hours, and very few (2\%) continuously sitting for more than 10 hours. These numbers indicate that IT people sit for long hours during their work, which impacts their lumbar spine. Such prolonged periods of sitting require a good ergonomic sitting posture [4] (this point was taken from red no 4 so added it).

In our study, we found that $67 \%$ of population were aware of correct postures in sitting while $27 \%$ of population were not aware of it and 6\% of the population didn't knew about the correct postures in sitting. Overall, only $48 \%$ of subjects imparted correct postures while sitting, while $52 \%$ of the population didn't follow correct sitting postures in their work place despite of being aware of the importance of using correct postures for daily routines. Past studies have also indicated that for better muscle endurance, better seats with lumbar support will aid in preventing back problems [4], and allow in maintaining the ideal sitting posture for long hours. A good abdominal core strength also contributes to having and maintaining a good posture [9]. In our study, the average value of lumbar core strength in males was measured at $63.51 \pm 2.60$, which was not significantly different from that for females of measure $63.4 \pm 2.59$.

In this study, fewer subjects (35\%) complained of low back pain while the majority (65\%) didn't have any complaints of low back pain. Out of 71 people who complained of low back pain, 63\% reported of pain becoming aggravated due to continuous sitting, while for the remaining 37\%, their lower back pain did not worsen from continuous sitting. The people who complained of pain showed a weak negative correlation with level of lumbar lordosis $(r=-0.12)$, which indicates that as lumbar lordosis increases the core strength is reduced, as compared to people who had no complaints of pain, and had no correlation with level of lumbar lordosis and lumbar core strength $(r=0.007)$. For previ studies that have expressed a relationship between the degree of lumbar lordosis and weakness of abdominal muscles as well as tightness of back extensor muscles, one has stood out. Williams et al. [10] recommended that the weakness of these muscles due to prolonged sitting is an important factor in increasing the lordosis angle. However, we found that there was no correlation between lumbar lordosis and lumbar core strength for IT professionals $(r=-0.042)$, which indicates that degree lumbar lordosis and core strength may be independent of each other.

In this study it was also seen that $51 \%$ of the total subjects participated in various recreational exercise forms such as walking, gym, yoga, sports and dance. Out of these walking was found to be the most preferable form of recreational training $(51 \%)$, while dance was found to be the least preferable choice of exercise activity, suggesting that walking as a recreational activity proved to be one of the most effective for building muscle strength.

Our study showed that there was no correlation between lumbar lordosis and lumbar core strength in IT professionals $(r=-0.042)$, indicating that lumbar lordosis and core strength are independent of each other. Hence, IT professionals should report low back pain as early as possible and seek medical help and any ergonomic advice 
if they think occupational exposure is harming them. For this population of workers, the combined efforts of the medical community, labor, and management should make an impact on this problem [4].

From our study, the result regarding the correlation between lumbar lordosis and lumbar core strength was only targeted to the IT population, and hence cannot be generalized to the broader population. However, changes in lordosis angle may be one of the contributing factors to low back pain and reduced core strength for the general population. Although lordosis curve evaluation is part of a routine physical examination in physiotherapy practice, measurement of lordosis angle with Flexicurve should be part of the general evaluation for back problems, including low back pain. An IT individual should seek help for low back pain for as early as possible and seek physiotherapy advice if they think occupational exposure is harming them [4].

There was one limitation to this study; namely, the number of subjects included in the study was relatively small, and a larger number of IT workers could have been included in the study to improve the predictability of the conclusions drawn. As previous studies have provided evidence that a difference exists in deep abdominal function of patients with and without low back pain, the pressure biofeedback unit may be considered a useful tool for assessment of lumbar core strength [11], and a pressure biofeedback unit was used as an assessment tool in our study. Although the inter-rater and intra-rater reliability of Flexicurve proved to be low in some of the previous studies $[5,12]$, Flexicurve proved to be a handy tool for assessment of lordosis, but the interpretation of curve on drawn on paper still remains tedious.

\section{Clinical implications}

In the present study it was found that there was no correlation between lumbar lordosis and core strength in IT population, indicating that lumbar lordosis and lumbar core strength may be independent of each other for the IT population. Therefore, IT professionals should seek proper ergonomics for their work place and follow it on a regular basis. This should be coupled to corrective exercises to improve posture in sitting; in addition, maintaining core strength should be promoted.

\section{Conclusions}

Lumbar lordosis and core strength have no correction in the IT population. Lumbar lordosis and lumbar core strength have a weak negative correlation for IT workers who complain of pain, but no correlation was seen for the IT population who do not complain of pain.

\section{Conflict of Interest}

No potential conflict of interest relevant to this article was reported.

\section{Acknowledgments}

We would like to thank all the subjects who willingly participated in the study, and all professors who gave their valuable guidance for the research. We would also like to thank Sancheti Institute College of Physiotherapy for supporting the research.

\section{References}

1. Magee DJ. Orthopedic physical assessment. St. Louis, Mo.: Saunders Elsevier; 2006.

2. Core stability [Internet]. Wikimedia Foundation Inc.; 2016 [cited 2016 May 14]. Available from: https:// en.wikipedia.org/wiki/Core_stability.

3. Lang-Tapia M, Espana-Romero V, Anelo J, Castillo MJ. Differences on spinal curvature in standing position by gender, age and weight status using a noninvasive method. J Appl Biomech 2011;27:143-50.

4. Levangie PK, Norkin CC. Joint structure and function : a comprehensive analysis. Philadelphia, PA: F.A. Davis Co.; 2005.

5. Pope MH, Goh KL, Magnusson ML. Spine ergonomics. Annu Rev Biomed Eng 2002;4:49-68.

6. Hinman MR. Interrater reliability of flexicurve postural measures among novice users. J Back Musculoskelet Rehabil 2003/2004;17:33-6.

7. Richardson C, Hodges PW, Hides J, Richardson C; Manipulation Association of Chartered Physiotherapists. Therapeutic exercise for lumbopelvic stabilization a motor control approach for the treatment and prevention of low back pain. New York: Churchill Livingstone; 2004. 
8. Nourbakhsh MR, Moussavi SJ, Salavati M. Effects of lifestyle and work-related physical activity on the degree of lumbar lordosis and chronic low back pain in a Middle East population. J Spinal Disord 2001; 14:283-92.

9. Youdas JW, Garrett TR, Egan KS, Therneau TM. Lumbar lordosis and pelvic inclination in adults with chronic low back pain. Phys Ther 2000;80:261-75.

10. Williams MM, Hawley JA, McKenzie RA, van Wijmen PM. A comparison of the effects of two sitting postures on back and referred pain. Spine (Phila Pa
1976) 1991;16:1185-91.

11. Cairns MC, Harrison K, Wright C. Pressure biofeedback: a useful tool in the quantification of abdominal muscular dysfunction? Physiotherapy 2000;86:12738.

12. Barrett $\mathrm{E}, \mathrm{McC}$ reesh $\mathrm{K}$, Lewis J. Intrarater and interrater reliability of the flexicurve index, flexicurve angle, and manual inclinometer for the measurement of thoracic kyphosis. Rehabil Res Pract 2013; 2013:475870. 